43. Shelford, V. E. \& Allee, W. C. The Reaction of Fishes to Gradients of Dissolved Atmospheric Gases. J. of Exper. Zool., 1913, 14, 207-266.

44. Shelford, V. E. The Reaction of Certain Animals to Gradients of Evaporating Power of Air. A Study in Experimental Ecology. Biol.Bull., 1913, 25, 79-214.

45. Stevens, H. C. Acquired Specific Reactions to Color (Chromatropism) in Oregonia gracilis. J. of Animal Behav., 1913, 3, 149-178.

46. Transene, N. von. Studien uber Temperaturwirkungen auf Daphnia magna, mit besonderer Berücksichtigung der Anpassungsercheinungen. Pfluger's Arch.f.d. ges. Physiol., 1913, 153, 323-352.

47. Vieweger, T. Recherces sur la sensibilitë des infusores (alcalio-oxytaxisme) les réflexes locomoteurs, l'action des sels. Arch. de biol., 1912, 27, 723-800.

48. Watson, J. B. \& Watson, M. I. A Study of the Responses of Rodents to Monochromatic Light. J. of Animal Behav., I9I3, 3, 1-14.

\title{
HABIT FORMATION, IMITATION AND HIGHER MENTAL PROCESSES OF ANIMALS
}

\author{
BY JAMES P. PORTER \\ Clark College
}

I

The first part of Johnson's monograph (7) is devoted to a thorough and critical review of the work on pitch discrimination in the dog. The results of Pavloff and Selionyi, on the saliva-reflex, that of Goltz, Munk, Kalischer, Rothmann and Swift on the effects of removal of the temporal lobes, inferior corpora quadrigemina and one or both cochlea leave the problems in an unsatisfactory state. All have used very crude behavior tests a fact which explains their widely divergent conclusions. The results of Johnson's experiments make up the second part of the monograph. He found that in from 6 to 44 days two female mongrel dogs, sisters, nearly four years old, learned to make the discriminations required in the following problems: ( 1 ) Discrimination between two tones, middle $C$ ( 256 d. v.) and $A$ above ( 384 d. v.), sounded on tuning forks struck by hand. (2) Discrimination between the two tones sounded on blown variators. (3) Discrimination between the two tones sounded on forks and on large and small variators indifferently. (4) Discrimination between chords containing one and the other stimulus tones respectively.

To the deeper tone the animals were required to place the fore-feet on a chair at the operator's left; to the higher one to mount a low box at the operator's right. In the case of an incorrect choice the animal was not fed. About two days after birth the edges of 
the lids of the eyes of both these dogs had been scarified and sewed together, thus assuring the continuance of temporary blindness. The results of these tests agree well with those of Kalischer and Rothmann.

Sixty days after learning the last problem each dog acted without error.

In another series of tests, 505 for each dog, in which experimenter, assistant, and stimulus-tone were outside the room in which the animal was placed when the tone was struck and in which she made her choice, there was little evidence of discrimination. They so behaved as to indicate that lack of attention and not inability to discriminate may be the explanation of their continued failure.

A stimulus-cage was constructed and electrically driven forks were used with König resonators to insure a practically pure tonestimulus, non-localizable by the human subject, and almost free from accessory noise, overtones and partials. Considerable diffculty was had for some three weeks to accustom the four dogs (two other younger females now being used) to the electric shock which was the punishment received when they turned into the wrong pathway. The problem was not learned in ninety days nor was there any sign of improvement. Thinking that the two tones might be too nearly alike, the problem of associating a tone $\mathrm{C}(256$ d. v.) with food in $F$ and release without a stimulus-tone food in $F^{\prime}$ was given; but the results in ten days (150 trials) were negative. It is an interesting fact that these four dogs in from 9 to 12 days did discriminate two noises made by two electric buzzers. Except in the case of $\operatorname{dog} 3$ they learned in about the same time to discriminate the noises when the buzzers had been interchanged in position. Position-habits were to be observed in most of the experiments.

The second part of the investigation was devoted to a comparison of the learning-time and learning-methods in blind and normal dogs. Six different puzzle-boxes were used, each with a different latch. Four more dogs were used in these tests making eight in all. The blind dogs had learned to behave ordinarily as normal, although none of their world was visual. How would they differ from normal dogs? Dogs 7 and 8 were also made blind in the same way as described for $I$ and 2 . The data gathered show that the dog is capable of learning to make complex adjustments and a large number of instinctive movements without the aid of vision. 
No dog lost more than ten per cent. in accuracy after a sixty-day interval. Control tests in total darkness gave results which indicate that the light had some stimulating effect on both blind and normal dogs. The other control test was to turn the box through $90^{\circ}$ from its original position, the first change setting practically a new problem for the animal. Other turns of $90^{\circ}$ disturb them less. This study shows that it is impracticable to attack the "Molyneux problem" by using dogs rendered temporarily blind. Tests on the blind dogs after their eyes were operated on to restore their sight and on normal dogs with rope and disoriented box suggest as to the experiments proper that even normal dogs may make little use of vision. They probably rely largely on kinæsthetic and muscular sense-processes. Given ten trials a day fewer days were required for learning than if twenty trials were given. Fatigue, monotony, and consequent lack of attention and effort are the probable explanations.

The experiments of Szymanski (I5) were made to determine if dogs (fox terriers) and cats can discriminate the different positions of the sounds made by an electric buzzer and learn to go for food only to the place at which the sound is made. Odors were eliminated as possible stimuli. The results were negative, the chief reason assigned being the small size of the room. Place-habits were marked in both dogs and cats though broken in the latter in two weeks. Preliminary habits indicated influence of having been fed previously by the experimenter. In these animals as in the white rats and in fish the past behavior is a large factor in present reactions. There are two stages in learning: the negative or partial loss of habit or inborn connection which are directly opposed to the new and growing habit; the positive or completion of the new and loss of the old. In tests without the sound stimulus but with change of distance and direction of food-box it seems to be indicated that there are two types in dogs; one motor, the other visual. Cats seem to be visual. The suggested explanation is that the former are animals of chase, the latter lie in wait.

The study of Sackett (12) is a definite attempt to combine the experimental and the natural history methods. In all 16 porcupines were used, natural conditions being obtained by out-door caves, dark dens, and natural food. Frequent journeys to the woods were made in order to observe their natural behavior. These animals are nocturnal and show little tendency to hibernate. When born the young are well developed even to the quills. If they 
play it is only while very young. Even the adults are easily tamed, eating out of the experimenter's hands one day after capture. They never thiow their quills. They make excellent subjects for experimental study. When offered food they first try to grasp it with the mouth. If this is prevented they readily grasp with the hand. In $\mathrm{I}_{2}$ out of $\mathrm{I}_{4}$ series of tests they used the right hand if the experimenter used his and similarly with the left. This is evidence that this animal is neither right nor left handed. The habit of taking food with one hand is very readily and thoroughly broken. To re-establish this old habit is almost as difficult as its initial formation. They are readily trained to respond to one kind of food with one hand, to another kind with the other hand. They can change the hand as often as the kind of food is changed. Brightness is the probable stimulus, cubes of sweet potato and carrot or cabbage being the foods used.

They learn to operate puzzle-boxes with four locks in a series. The results with this apparatus as in all other experiments demonstrate that in ability to discriminate and learn the porcupine is practically on the same level as the raccoon and the monkey. Unsuccessful attempts were made to determine the porcupine's ability to discriminate tones of different pitch. The cochlea is complex and the sounds made by the animal itself cover a wide range. The forms used were made with the denning proclivities of the animal in mind. There was some evidence that but part of the form was the basis of discrimination which was probably kinæsthetic as well as visual. The brightness discrimination is about 10 shades of the Nendel series. It may be finer than this for the grays at the ends of the series. They probably can not discriminate color when tests are made with colored papers. No account of the area of acute vision has been found in the literature. Rotation of the maze $90^{\circ}$ and later another $90^{\circ}$ was a source of confusion to the animals though less following repeated rotation. After once learning the maze they were able to follow it in the dark. Learning it in darkness differed little from learning in daylight. Memory tests after a Ioo-day interval show little if any loss of ability. Tests in which there is more of the kinæsthetic in relation to the visual show better retention.

After verifying Graber's investigations, which proved that cockroaches avoid light and seek the dark Szymanski (13) sought to so modify by the punishment method the responses that these insects would seek the light and avoid the dark. The strength of shock 
to be used was first carefully determined in preliminary trials. The insects used were male larvæ about one and a half years old, the apparatus being cleansed aftei each series of tests.

As the insect entered the dark end of the box the current was turned on, as it retreated to the light end the current was turned off. Learning was considered complete when the insect, being in the light, turned back to light ten times on the boundary line, without receiving a shock. The time required for training with all of the ten animals except nos. 3 and 5 was on the average from three quarters to one hour. These two suffered from such great fatigue that their training could not be completed in one day. The analysis of the results and curves gives two factors, practice and fatigue hence a special case of Kraepelin's "Arbeitscurve." In the length of time during which they retained this new habit they show marked individual differences. There is no evident relation of permanency of this new habit and the number of shocks required to establish it. The training is evident in their behavior for only a short time but they relearn the habit after only a few shocks. It is possible to establish the habit in an insect with the antennæe removed. These results do not support the statements of $F$. Plateau concerning bumble-bees and other insects.

A brief account of the same results is given in a second article by the author (I4).

The purpose of the paper by Gregg and McPheeters (3) is critical. Cole's "card-displayer" apparatus was duplicated and experiments repeated but with the experimenters hidden by a screen and in the control series the color cards were removed and the levers used alone, the levers were so operated that they were not visible to the animals but still made their usual sound. A series of two sounds invariably called out the normal response in the raccoon. Four and five sounds were given and the results enable the authors to state that any completed series of sounds is the sensory stimulus. The two raccoons used may have and use images. The results obtained under the ingenious controls strongly suggest that the "stimulus-response" type of behavior is the only one exhibited by Cole's raccoons as well as by the two subjects of the present experiments.

The brief paper by Lashley (8) is a record of incomplete observations and experiments on a large Amazon (Chrysotis sp.) parrot imported in 1892 and which had learned to speak about 60 words some of which were combined into phrases. He made a number of 
inarticulate sounds distinguishable from instinctive notes. These are given most often in response to a visual or auditory stimulus, more frequently the latter. These inarticulate sounds-"singing, whistling, barking, mewing, cuckling, and coughing"-offer the best material for experiment because of their wide qualitative range and they are given in response to auditory stimulation. In two series of experiments on timbre and one on pitch it was found that the bird distinguishes and reproduces the musical tones and the pitch of the stimulus. There was no evidence of imitation of two or more successive tones. Capacity for circular imitation may be developed largely by conditions of captivity. The impulse to imitate is probably connected with the sexual life.

Lashley and Watson (9) have reported notes regarding the physical and mental development of a monkey. The subject of these observations was a young Macacus rhesus monkey conceived and born in captivity. At birth the little monkey was far advanced physically. In sensory-motor development it was far superior to the human infant and the rate of development during the first fifteen weeks (the period observed) was remarkably rapid.

From general observations of the orangs and chimpanzees Haggerty (6) came to question the adequacy of the "sense-impulse" theory of animal learning. The animals experimented on were two strong, docile, female orangs and a quick nervous male chimpanzee. Betty at once and Nancy after some looking at the apparatus used in the best possible way a stick with a hook on the end to secure food which was on a table outside the cage and beyond their reach. Baldy made no effort to use the stick. Betty used a stick to get food from inside a pipe. Baldy failed in this also and showed no signs of imitating the successful behavior of the others. Nancy repeated the behavior of Betty in the pipe experiment in such a way as to lead the experimenter to conclude that she gave certain evidence of "inferential imitative behavior." With both orangs he obtained results which indicated that, though there is some use of the "trial and error" method there is also something above the mere sense-experience level, that is, a low order of rationality. One can not but wonder as to the previous experience of these animals in its bearing on the solution of the present problems.

The horses of Elberfeld continue to attract attention. Claparède (2) returned to Elberfeld for three days for new observations and to make the crucial test of putting to the horses numbers and problems on cards drawn at random and unknown to any one 
present. It was found that of all the horses-Hans, Zarif, Muhamed, Hänschen, and blind Berto, the last made fewer mistakes than any other even when the assistant was not near him. There were mistakes both when the questioner knew the answer and when he did not. Since Claparede's first article in vol. 12 of the same Archives many others have appeared. A large part of his present paper is devoted to review and criticism. Fraud and trickery are dismissed as impossible as are also unconscious visual, auditory, or tactual signals. Some believe that the horses work out the answers to problems in cube root by themselves. Chance is ruled out and there are too many problems solved for memory to be the explanation.

The "protest" from Germany is dogmatic, unscientific, negative, unsympathetic. Instead of "protest" get other horses and investigate. Then refute. A letter by Dr. J. de Modzelewski is published in which he tries to refute all explanations except that of telepathy. He gives as the percentages of right answers in four series of tests with Zarif, Muhamed, Berto, and Hänschen, II per cent., I 3 per cent., $7 \frac{1}{2}$ per cent., and I I per cent. One is, however, not convinced when he says telepathy explains it all. Professor Claparède concludes in favor of a process of thinking peculiar to these animals, the full proof for which has not yet been given.

Haenel (4) was present in experiments with the Elberfeld horses when the halter was no longer used by the trainer. $\mathrm{He}$ could see no signals. Other visitors could see none, particularly in the work of Krall, and the horses replied correctly. The gradual increase in the number of right answers, the changing mood of the horses, the types of mistakes, such as confusing units and tens, the phonetic spelling and consonant, ungrammatical method of expression, answers opposed to suggestion and expectation, and the exclusion of all mechanical and mental helps are conclusive proofs to Haenel that the horses "think."

The dog, Rolfe, whose performances are reported by Mackenzie (Io) has been trained to reply to questions by tapping the floor with his foot, I I times for $G$, I4 times for $K$, etc. The trainer is a woman of very delicate and artistic temperament and a semiinvalid. Other dogs and a cat have also been educated as "Rolfe" has. Of himself Rolfe began to make combinations which his trainer decided stood for letters. He never makes any errors and uses the patois of the Mannheim peasants and the smallest numbers for letters in most frequent use. He is said to have a system of 
stenography as do the horses-s-n is essen. Vowels are often omitted. Not only is he said to know grammar but he can give sentences to illustrate rules. He is very easily fatigued.

At three separate times but with the trainer present the author tried the dog with pictures on cards which were drawn from envelopes so that no person, not even himself, could see. The dog after rapping 4, "tired," spelled "Rot, blau, Eck" which was correct. As many as ten resemblances between Rolfe and the Elberfeld horses are pointed out. The author rather characteristically closes his article with a plea for the return to the old dual conception of mind as reason and intuition. The order of increasing reason may be horse, dog, man, but the reverse for intuition.

Larguier des Bancels and Claparède succeeded in holding a single session with "Rolfe." From a series of cards previously prepared one was chosen and shown to the dog in such a way that the trainer or assistants probably could not see the picture on the card. After considerable reluctance the dog spelled out the words which described fairly well the pictured objects. The dog's illness prevented them from submitting him to more rigid tests on the following day. The question of his spontaneous use of speech thus remains unsolved.

Parker (II) discusses the subject of adaptation in relation to intelligence. No feature of organic life has received greater emphasis than adaptation. We are just learning that to think of an organism as a machine standing still is to divest it of that which is most distinctive. Adaptation is an essential of dynamic activity. But this activity which is continuous determines the adaptations. Classed alone adaptations have been unduly emphasized. Many reactions have been called adaptations which are not. Animal reactions, the author believes, are in the main free from adaptive restraint. They depend upon the fluctuating momentary conditions of the animal body. They are adaptive only in main outlines. If we attempt to explain this condition by assuming something like intelligence we are arguing in a circle, for intelligence is our own name for our own chief means of adaptation.

Burroughs's article (I) is written in criticism of the study of animal behavior in the laboratory as set forth in an earlier paper by Professor Haggerty. ${ }^{1}$ In such study animals are drilled in to forming new habits, the reasons for which they do not understand. Intelligence, strangely used by Mr. Burroughs, is, for the most part,

1 Atlantic Monthly, May, 19r3. 
conspicuously lacking. The gulf between the mind of man and of animals is so great that he believes it is misleading to describe so-called animal psychology in terms of human psychology. The reason the laboratory student finds so little of "intelligence" in animals is that the problems he sets are human problems, the situations are so foreign to the animals. His use of the word intelligence is yet more strange when he says that plants show it in the devices for scattering seed, securing cross-fertilization, etc. The laboratory student has animal behavior in a nut-shell and is therefore without perspective. If an exact science of animal behavior is possible then the laboratory student has the advantage; yet such is an impossibility in the laboratory or out of it.

Those animals that are self-armed, like the porcupine, Burroughs asserts, are slow and dull of wit. The reviewer is here constrained to ask the author to examine the results obtained by Dr. Sackett on the porcupine, the review of which will be found above.

The experimentalists should prove or disprove that birds are color-blind and other like problems because such would furnish a crucial test of such large questions as Darwin's natural selection theory. He wishes that the experimentalists would determine what is the sense which enables one bird to pursue another so unerringly and how gregarious birds fly as a unit. The human experiences which we call telepathy are the survivals of this lost human capacity. He closes his discussion by saying that there is little or no value in such investigations as that of the tactual sensations of the white rat unless they yield the key to some larger problem.

Mr. Burroughs will find it difficult to justify his use of the term intelligence. He assumes that telepathy is a proven fact in human psychology and is I believe in error in his facts or interpretations concerning porcupines and the unity of response in the aerial evolution of birds. Other explanations should be long tried before resorting to mental telepathy.

Haggerty's article (5) gives the contrary viewpoint. Like Mr. Burroughs every student of animal behavior regrets that careful experimentation requires so much time. All would like to state the whole truth about tropisms or mental evolution in one sentence. Haggerty cites the experiments by Dr. Hamilton, the results of which have been published, on eight normal human beings-men, boys and girls, - two defectives, five monkeys, sixteen dogs, five cats, and one horse, which prove that any one who believes in a 
qualitative difference between the animal and human mind has a difficult task to give a satisfactory explanation of such facts. These experiments would also seem to prove that animals do not respond in an invariable manner peculiar to their species while man has the possibility of wide variation. They also show that there is much animal behavior in man and some human behavior in dogs and monkeys. For Mr. Burroughs to deny that animal behavior can ever become an exact science is a denial of all real science. The experimental method must be used just because of the complexity of nature and it is being extended to even education, religion and eugenics. On its tangible results depends our entire social organization.

The movement for the experimental study of animal behavior has been created within the past decade or so and has accomplished much. A fact has no more or less virtue for having been discovered experimentally or by an observing naturalist.

\section{REFERENCES}

I. Burrougrs, J. Animal Wit Indoors and Out. Allantic Mo., 1912, 109, 196-205.

2. Claparède, E. Encore les chevaux d'Elberfeld. Arch. de Psychol., 1913, I3, $244^{-284}$.

3. Gregg, F. M. \& McPheeters, C. A. Behavior of Raccoons to a Temporal Series of Stimuli. J. of Animal Behav., 1913, 3, 241-259.

4. Haener, H. Zum Problem der Elberfelder Pferde. Zsch.f. angew. Psychol., 19r3, $7,530-546$.

5. Haggerty, M. E. Upon the Threshold of the Mind. Atlantic Mo., 1913, I12, $245-253$.

6. Haggerty, M. E. Plumbing the Minds of Apes. McClure's Mag., 1913, 41, 151I54.

7. Johnson, H. M. Audition and Habit Formation in the Dog. Behav. Monog., I913, 2 (No. 8). Pp. iv +78.

8. LAshley, K. S. Reproduction of Inarticulate Sounds in the Parrot. J. of Animal Behav., 1913, 3, 36I-366.

9. Lashley, K. S. \& Watson, J. B. Notes on the Development of a Young Monkey. J. of Animal Behav., I9I3, 3, II 4 -I39.

10. Mackenzie, W., Larguier des Bancels, J., \& Claparède, E. Le Problème du chien pensant de Mannheim. Arch. de Psychol., r9r3, 13, 312-376; 377-379.

Ir. Parker, G. H. Adaptation in Animal Reactions. Amer. Natural., 1913, 47, $83-89$.

12. Sacketr, L. W. The Canada Porcupine: A Study of the Learning Process. Behav. Monog., 1913, 2, No. 2. Pp. iii +84 .

I3. Szymanski, J. S. Modifications of the Innate Behavior of Cock-roaches. J. of Animal Behav., 1912, 2, 8I-90.

14. Szymanski, J. S. Aenderung des Phototropismus bei Küchenschnaben durch Erlernung. PFLügen's Arch. f. d. ges. Physiol., 1912, 132-134.

15. Szymanski, J. S. Lernversuche bei Hunden und Katzen. Pflúger's Atch. f. $d$. ges. Physiol., 1913, 152, 307-338. 